\title{
Endodontic management of single rooted immature mandibular second molar with a single canal using MTA-A case report
}

\author{
Ramesh Kumar M. ${ }^{1}$, Bizenzah C. P., ${ }^{2, *}$ Elsy P. Simon ${ }^{3}$, Ravi S. V. ${ }^{4}$, Chandini Raveendran ${ }^{5}$ \\ ${ }^{1}$ Professor \& HOD, ${ }^{2}$ PG Student, ${ }^{3}$ Professor, ${ }^{4}$ Reader, ${ }^{5}$ Senior Resident, Dept. of Conservative \& Endodontics, KMCT Dental \\ College, Kozhikode, Kerala, India
}

*Corresponding Author:

Email: bze.bds@gmail.com

\begin{abstract}
An immature tooth with necrotic pulp and periapical pathology imposes a great difficulty to the endodontists. The case becomes more difficult when the clinician comes across a rare presentation of tooth morphology. Endodontic treatment options for such teeth consist of conventional apexification procedures. This article demonstrates the recent concept of mineral trioxide aggregate (MTA) apical plug technique, for the management of a single rooted immature second molar with a single continuous canal.
\end{abstract}

Keywords: Apexification, apical plug, mineral trioxide aggregate, necrotic teeth with immature apices.

Abbreviations: CH-Calcium Hydroxide, MTA-mineral trioxide aggregate.

\section{Introduction}

Non-surgical endodontic treatment aimed at the retention of teeth with a necrotic pulp comprises thorough cleaning and shaping, followed by threedimensional obturation of the root canal system. ${ }^{1,2}$ Knowledge of dental anatomy is an essential tool for the success of endodontic treatment. A clinician is required to have an insight of the morphology of tooth related to its shape, form and structure before commencing treatment.

Generally anatomical configuration of mandibular second molar is that of two roots, mesial and distal, it is seen closer together than the first mandibular molar, it can also be fused to a single conical root with varying internal anatomy and often have c-shaped canal configuration. Root fusion that becomes a single-root, conical, or "C-shape" form has an incidence of approximately $21.8 \% .^{3}$ C-shaped canal system is commonly found in mandibular second molars especially in Asian population. But the presence of single canal with a round or oval orifice in a second mandibular molars has been reported only rarely. A study by Weine et al. reported that $1.3 \%$ of mandibular second molars have single canal configuration. ${ }^{4}$ In another study conducted by Yang ZP et al. in Chinese population he found cone-shaped roots in only $2.1 \%$ of the second mandibular molars. ${ }^{5}$ The data from six anatomical studies that differentiated single conical and $\mathrm{C}$-shaped roots indicate that the incidence of these two canal systems is approximately equal $(8.3 \%$ and $8.5 \%$, respectively). ${ }^{3}$

The treatment of immature teeth poses many challenges for the clinician, one of which is the lack of an apical stop, which makes controlled obturation in three dimensions demanding if not impossible. ${ }^{6}$ In addition, the dentinal walls of an immature root may be very thin, thereby subjecting the tooth to the risk of fracture. ${ }^{7,8}$
Various ways of managing tooth with a wide open apex have been suggested. These include obturation of the root canal with a customised blunt-ended guttapercha cone, ${ }^{9}$ filling the root canal short of the apex with gutta-percha ${ }^{10}$ or peri-radicular surgery, ${ }^{11}$ or apexification procedures. Traditionally, the apexification method involves application of calcium hydroxide $(\mathrm{CH})$ until completion of root-end closure. ${ }^{12,13}$ However, the disadvantages of this longterm technique include delayed treatment, difficulty in following up with patients, unpredictability of an apical seal, and the risk of root fractures because of the presence of thin walls. ${ }^{14}$ Filling of the root canals with $\mathrm{CH}$ dressing for extended periods may weaken tooth structure. $^{15}$

Apical closure in immature teeth may also be achieved by placement of an artificial apical barrier, allowing prompt obturation and restoration ${ }^{11}$. Mineral trioxide aggregate (MTA) has been introduced as the material of choice for this technique numerous clinical studies showing favourable results, comparable or superior to apexification with calcium hydroxide. MTA has many characteristics making it a suitable apical barrier material, including biocompatibility, sealability, low cytotoxicity and induction of a favourable tissue response ${ }^{16}$.

This case report highlights the occurrence and management of single rooted mandibular second molar with open apex of the single canal, using MTA Angelus (Angelus Dental Solutions, Londrina, Parana, Brazil).

\section{Case Report}

A 15-year-old female patient came to the endodontics department of our college, complaining of pain in relation to the left mandibular posterior region, since 1 month. Patient also reported a history of severe spontaneous pain two weeks back, for which the patient took medications and the pain subsided. Medical 
history was non-contributory. Intraoral examination revealed deep caries. The tooth was also tender on percussion. Intraoral periapical radiograph of the tooth revealed deep caries involving the pulp with associated periapical pathology and open apex. Vitality test for heat and cold were suggestive of irreversible pulpitis. A detailed examination of the radiograph revealed the presence of a single root with a wide canal. The apexification treatment was explained to the patient's parents, and the decision for apexification instead of revascularization was made primarily because the diameter of the open apex was not more than $1 \mathrm{~mm}$, which may be difficult to induce bleeding.

\section{First Appointment}

Endodontic access opening was done under local anaesthesia and rubber dam isolation. On observation of the pulpal floor, only one canal with a round or oval orifice was located, suggestive of the presence of a single canal (Fig. 1). Further exploration of the pulpal floor did not reveal presence of any additional orifice opening. A \#15 K-file was introduced into the canal to ensure the patency of the canal and a periapical radiograph was taken to determine the working length. The root canal was enlarged using circumferential filing technique with hand $\mathrm{K}$ file up to ISO size 70, under irrigation with copious amounts of $2.5 \%$ sodium hypochlorite. The root canal was then dried with sterile paper points. A calcium hydroxide paste (Metapex; Meta Biomed, Chungju, Korea) was placed into the apical portion of canal with a lentulo spiral as intracanal medication. The access cavity was closed with a cotton pellet and glass ionomer cement (Fig. 2). The patient was scheduled for a second visit after 1 week.

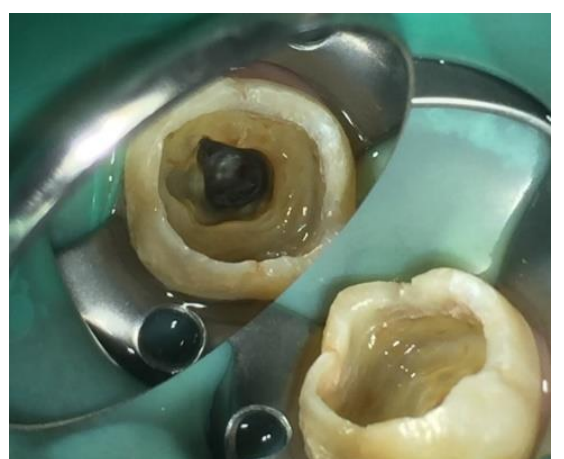

Fig. 1: The pulpal floor observed in first appointment with only one canal with a round or oval orifice was located, suggestive of the presence of a single canal

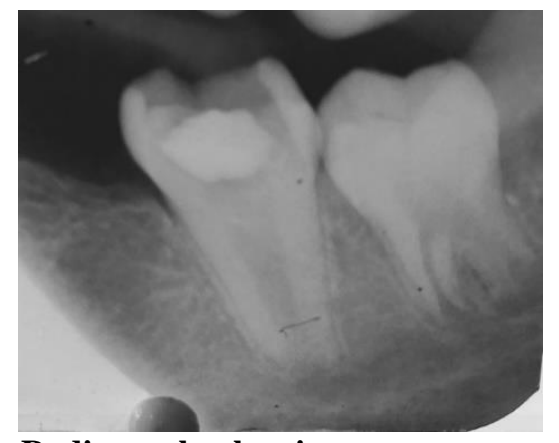

Fig. 2: Radiograph showing open apex and the access cavity closed with a cotton pellet and glass ionomer cement

\section{Second Appointment}

The tooth was asymptomatic during the entire postoperative period, and the temporary restoration was intact. Local anaesthesia was accomplished. After isolation with rubber dam, the glass ionomer and cotton pellet were removed from the access cavity. A copious amount of $2.5 \%$ sodium hypochlorite and a rinse of $17 \%$ EDTA for 1 minute was performed followed by a final rinse with normal saline. The canal was dried with paper points.

MTA Angelus (Angelus Dental Solutions, Londrina, Parana, Brazil) was mixed according to the manufacturer's instructions, and a 4-mm-thick apical plug was created. The MTA was introduced into the apical portion of the canal from the orthograde direction with a Messing gun (MTA Endo Gun, Dentsply Maillefer, Ballaigues, Switzerland) and adapted to the canal walls with an endodontic plugger (Figure 3). Correct placement of the MTA was confirmed with a radiograph (Fig. 4). The access chamber was temporarily filled with a cotton pellet dampened with sterile water and Cavit.

\section{Third Appointment}

During the next appointment, the next day, after the isolation of the tooth by means of a rubber dam, obturation of the canal was completed using thermoplasticized gutta percha technique (Fig. 5). The teeth were restored with a dentin bonding agent and resin composite, and an immediate post-treatment radiograph was taken. 


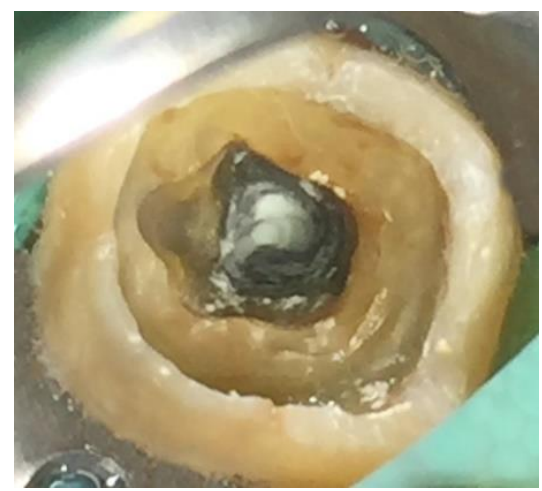

Fig. 3: Application of MTA in the canal

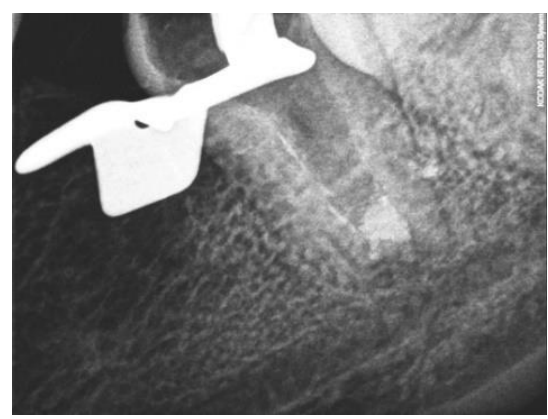

Fig. 4: Correct placement of the MTA was confirmed with a radiograph

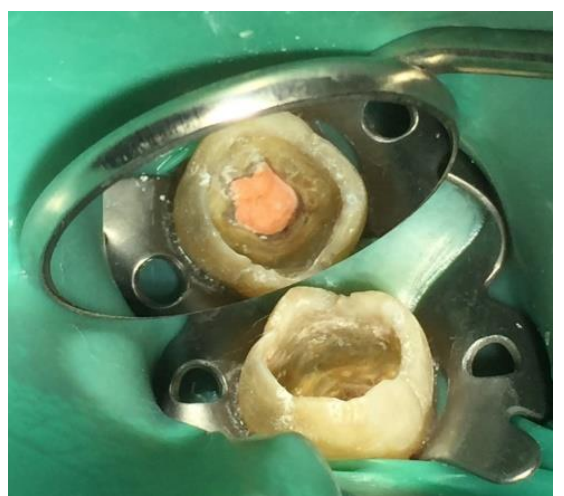

Fig. 5: Obturation of the canal was completed

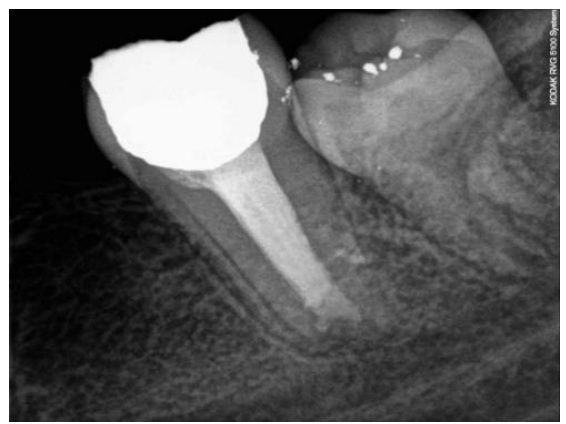

Fig. 6: Follow up radiograph after 6 months

\section{Follow-up}

At follow-ups performed at 3, 6 months after treatment the tooth was asymptomatic, and the colour of the crown did not change. The continuity in the periodontal ligament space with absence of periapical radiolucency was observed at 3-months and 6-months (Fig. 6).

\section{Discussion}

A thorough knowledge of the anatomy of teeth involved in root-canal treatment is essential for successful debridement and obturation of the root-canal system. Recognition of unusual canal configurations and variations are paramount, because it has been established that the root with a single tapering canal and apical foramen is the exception rather than the rule by Abou-Rass et al. ${ }^{17}$

Of particular interest is the canal configuration of the mandibular second molar as a great deal of variation can occur. Fan et al. in 2004 modified Melton's method of classification of " $\mathrm{C}$ " shaped canal, according to which the current case falls into category III (C3). Clearly, the recognition of these configurations facilitates cleaning, shaping, and obturation. ${ }^{18}$

Studies on mandibular second molars have shown a high incidence of C-shaped roots and canals (10\%$31.5 \%$ ) in Japanese (28), Chinese (17), Hong Kong Chinese (6), Lebanese (18), and Thai (29) populations. These studies indicate that $\mathrm{C}$-shaped canals are more frequent in Asians, especially from the Far East. More studies have to be conducted in Indian population to report the incidence of these. ${ }^{19}$

Apexification is defined as a method of inducing a calcified apical barrier or continued apical development of an incompletely formed root in teeth with necrotic pulp. ${ }^{20}$ One-visit apexification, in its traditional sense, has been described in the literature as the non-surgical compaction of a biocompatible material into the apical end of the root canal, thus creating an apical stop and enabling immediate obturation of the root canal. ${ }^{21}$

In most apexification protocols involving human immature permanent teeth with apical periodontitis, the placement of an apical plug is crucial for sealing and preventing bacterial leakage. ${ }^{22}$ Because MTA had been introduced by Torabinejad and co-workers for use in pulp capping, pulpotomy cases, and sealing accidental perforations of the root canal, ${ }^{23}$ it became the material of choice for apexification therapy because of excellent biocompatibility and sealing ability. ${ }^{24}$ Various properties of MTA suggest its usefulness in cases where one-visit apexification is desired.

MTA produces apical hard tissue formation with significantly greater consistency than $\mathrm{CH}^{8}{ }^{8}$ A systematic review comparing the efficacy of MTA and $\mathrm{CH}$ as material used for apexification of immature teeth revealed no significant differences between both groups regarding success and apical barrier formation, ${ }^{25}$ although the time taken for formation of apical biological calcified barriers in immature teeth treated with MTA was significantly less than the time for those treated with $\mathrm{CH},{ }^{26}$ Eli-Meligy and Avery ${ }^{27}$ compared MTA and CH clinically and radiographically as materials to induce apexification in 15 children, each 
with 2 necrotic immature permanent teeth. The 12month follow-up revealed failure in only 2 teeth treated with $\mathrm{CH}$ because of persistent periradicular inflammation and tenderness to percussion. None of the MTA-treated teeth showed any clinical or radiographic pathology.

Pace $\mathrm{R}$ et $\mathrm{al}^{28}$ in their 10-year follow-up study, evaluated the clinical and radiologic outcomes of teeth with necrotic pulp, immature apices, and periapical lesions treated with the mineral trioxide aggregate (MTA) apical plug technique concluded that the apical plug with MTA was a successful and effective technique for long-term management of this group of teeth with necrotic pulps with immature root development and periapical lesions. Many authors have demonstrated the viability of a fibroblast cell line in contact with MTA. Zhou et $\mathrm{al}^{29}$ showed that human gingival fibroblasts in contact with MTA attached to and spread over the material surface at 7 days of culture.

The total treatment time taken for the patient was only 8 days, which was very favourable when compared to calcium hydroxide, where a recent prospective clinical trial reported an average of 12.19 months required for completing treatment. ${ }^{30}$ In a recent systematic review by Lin. JC et $\mathrm{al}^{31}$ comparing MTA and $\mathrm{CH}$ they concluded that while both materials provide similar success rates, the shorter treatment time with MTA may translate into higher overall success rates because of better patient compliance.

\section{Conclusion}

Knowledge of dental anatomy is an essential tool for the success of endodontic treatment. This case report has appended to the fact that, a clinician is required to have an insight of the morphology of tooth related to its shape, form and structure before commencing treatment and white MTA used as an apical barrier material following an initial dressing with calcium hydroxide in immature permanent single rooted mandibular second molar with a single canal produces excellent clinical results. Shortened treatment time, predictable apical stop and acceptability make the use of white MTA an attractive treatment option for nonvital immature teeth in children and adults.

\section{References:}

1. Schilder $H$. Filling root canals in three dimensions. Dent Clin North Am 1967; I I:723-44.

2. Schilder $H$. Cleaning and shaping the root canal. Dent Clin North Am 1974;18:269 -96.

3. Ingle JI. Ingle's endodontics 6. PMPH-USA; 2008;Pg 209

4. Weine FS, Pasiewicz RA, Rice RT. Canal configuration of the mandibular second molar using a clinically oriented in vitro method. J Endod. 1988;14:207-13.

5. Yang ZP, Yang SF, Lin YC, Shay JC, Chi CY. C-shaped root canals in mandibular second molars in a Chinese population. Dental traumatology. 1988 Aug 1;4(4):160-3.

6. Abbott P V Apexification with calcium hydroxide - when should the dressing be changed? The case for regular dressing changes. Aust Endod J 1998:24:27-32.

7. Hachrneister D.R. Schindler WG., Walker WA. 3rd, Thomas D.D. The sealing ability and retention characteristics of mineral trioxide aggregate in a model of apexification. J Endod 2002; 28: 386-90.

8. Shabahang S., TorabinejadM., BoynePP. Abedi $H$. McMillan $P$. A comparative study of root-end induction using osteogenic protein- I, calcium hydroxide, and mineral trioxide aggregate in dogs. J Endod 1999;25:1-5.

9. Pollack. Endodontia for- non-vital teeth with incompletely formed roots. Bull NJSoc Dent Child 1967; 4: 2-6.

10. Moodnick $R$. Clinical correlation of the development of the root apex and surrounding structures. Oral Surg Oral Med Oral Pathol 1963; 16: 600-7.

11. Witherspoon D.E., Ham K. One-visit apexification: technique for inducing root-end barrier formation in apical closures. Pract Proced Aesthet Dent 200 I; 13: 455 60; quiz 62.

12. Seltzer S. The root apex. In: Seltzer S, Krasner P, eds. Endodontology: Biologic Considerations in Endodontic Procedures. Malvern, PA: Lea \& Febiger; 1988:1-30

13. Rafter M. Apexification: a review. Dent Traumatol 2005;21:1-8.

14. Shabahang S. Treatment options: apexogenesis and apexification. Pediatr Dent 2013;35:125-8.

15. Andreasen JO, Farik B, Munskgaard EC. Long-term calcium hydroxide as a root canal dressing may increase the risk of root fracture. Dent Traumatol 2002;18:134-7.

16. Moore A, Howley MF, O'Connell AC. Treatment of open apex teeth using two types of white mineral trioxide aggregate after initial dressing with calcium hydroxide in children. Dental traumatology. 2011 Jun 1;27(3):166-73.

17. Abou-Rass M, Frank AL, Glick DH. The anticurvature filing method to prepare the curved root canal. The Journal of the American Dental Association. 1980 Nov 1;101(5):792-4.

18. Fan B, Cheung GS, Fan M, Gutmann JL, Bian Z. Cshaped canal system in mandibular second molars: Part I-Anatomical features. J Endod 2004;30:899-903.

19. Jafarzadeh $\mathrm{H}, \mathrm{Wu} \mathrm{YN}$. The $\mathrm{C}$-shaped root canal configuration: a review. Journal of endodontics. 2007 May 31;33(5):517-23.

20. AAE Glossary - Contemporary Terminology for Endodontics. American Association of Endodontists, Chicago, 2015.

21. Morse D.R., O'Lornic ., Yesilsoy C. Apexification: review of the literature. Quintessence Int 1990; 2 I: 589 98.

22. Holland GR. Periapical response to apical plugs of dentin and calcium hydroxide in ferret canines. J Endod 1984;10:71-4.

23. Lee SJ, Monsef M, Torabinejad M. Sealing ability of a mineral trioxide aggregate for repair of lateral root perforations. J Endod 1993;19:541-4.

24. Torabinejad M, Parirokh M. Mineral trioxide aggregate: a comprehensive literature review- part II: leakage and biocompatibility investigations. J Endod 2010;36: 190202.

25. Chala S, Abouqal R, Rida S. Apexification of immature teeth with calcium hydroxide or mineral trioxide aggregate: systematic review and meta-analysis. Oral Surg Oral Med Oral Pathol Oral Radiol Endod 2011;112:36-42.

26. Pradhan DP, Chawla HS, Gauba K, et al. Comparative evaluation of endodontic management of teeth with unformed apices with mineral trioxide aggregate and calcium hydroxide. J Dent Child (Chic) 2006;73:79-85. 
27. El-Meligy OA, Avery DR. Comparison of apexification with mineral trioxide aggregate and calcium hydroxide. Pediatr Dent 2006;28:248-53.

28. Pace R, Giuliani V, Nieri M, Di Nasso L, Pagavino G. Mineral trioxide aggregate as apical plug in teeth with necrotic pulp and immature apices: a 10-year case series. Journal of endodontics. 2014 Aug 31;40(8):1250-4.

29. Zhou HM, Shen Y, Wang ZJ, et al. In vitro cytotoxicity evaluation of a novel root repair material. J Endod 2013;39:478-83.

30. Dominguez Reyes A, Muñoz Muño L, Aznar Martı'n T. Study of calcium hydroxide apexification in 26 young permanent incisors. Dent Traumatol 2005;21:141-5.

31. Lin JC, Lu JX, Zeng Q, Zhao W, Li WQ, Ling JQ.

Comparison of mineral trioxide aggregate and calcium hydroxide for apexification of immature permanent teeth: A systematic review and meta-analysis. Journal of the Formosan Medical Association. 2016 Jul 31;115(7):523 30. 